\title{
IMPLEMENTASI SISTEM PENGGAJIAN PADA PT. DWI PRATAMA TEKNIK DENGAN METODE PIECES
}

\author{
${ }^{1}$ Aisah, ${ }^{2}$ Sugiyono* \\ ${ }^{1}, 2$ Teknik Informatika Sekolah Tinggi Ilmu Komputer Cipta Karya \\ Informatika \\ Jln. Raden Inten II No. 8A, Duren Sawit, Jakarta - DKI Jakarta, Indonesia \\ e-mail: abintiumar11@gmail.com, inosoguy007@gmail.com, mahvin2012@gmail.com
}

Received: 2021-08-25, Revised: 2021-08-30, Accepted: 2021-09-02

\begin{abstract}
Abstrak
PT. Dwi Pratama Teknik (DPT) merupakan sebuah perusahaan yang bergerak dibidang kelistrikan dengan jasa infrastruktur elektrikal dan mekanikal. Saat ini memiliki karyawan yang semakin bertambah seiring dengan berkembangnya PT. Dwi Pratama Teknik (DPT). Salah satu hal yang sangat diperhatikan dengan bertambahnya karyawan adalah pengelolaan dalam sektor penggajian. Di dalam sektor penggajian yang masih menerapkan sistem penggajian secara manual dan konvensional. Untuk memudahkan pengolahan dalam penggajian, laporan dan slip gaji karyawan dibutuhkan sistem informasi penggajian karyawan yang dapat membantu dalam pengolahan data-data penggajian. Berdasarkan permasalahan tersebut maka dilakukan penelitian untuk memperoleh kebutuhankebutuhan yang diperlukan untuk membangun sistem informasi penggajian karyawan. Pembangunan sistem informasi dimulai dengan proses analisis dengan menggunakan metode pieces dan dilanjutkan dengan sistem perancangan yang didasarkan pada hasil analisis kebutuhan. Tahap terakhir dari proses penyusunan sistem ini adalah implementasi perancangan sistem menjadi sebuah sistem baru. Dapat disimpulkan bahwa sistem informasi penggajian karyawan yang dibangun dapat membantu dalam pengolahan data penggajian serta dapat menampilkan informasi yang dibutuhkan oleh karyawan PT. Dwi Pratama Teknik (DPT).
\end{abstract}

Kata kunci: sistem informasi, penggajian karyawan, web, pieces

\begin{abstract}
PT. Dwi Pratam Teknik is a company engaged in electrical with electrical and mechanical infrastructure service. Currently has employees who are increasing along with the development of PT. Dwi Pratama teknik. Of the things that is very concerned with the increase in employees is management in the payroll sector. In the payroll sector which still applies the manual and conventional system. To facilitate processing in payroll, report and employee salary slips, an employee payroll information system is needed that can assist in processing payroll data. Based on these problems, research was conducted to obtain thr requirement needed to build an employee payroll information system. The development of the information system begins with an analysis proses using the pieces method and continues with a system design based on the results of the needs analysis. The last stage of the process of compiling this system in the implementation of the system design into a new system. It can be concluded that the employee payroll information system that was built can assist in processing payroll data and can display information needed by employees of PT. Dwi Pratama Teknik.
\end{abstract}

Keyword: Information system, employee payroll, web, pieces

This work is licensed under a Creative Commons Attribution 4.0 International License.

http://journal.stmikjayakarta.ac.id/index.php/JMIJayakarta 
DOI: $10.52362 /$ jmijayakarta.v1i4.545

\section{PENDAHULUAN}

Penggajian merupakan salah satu hal yang penting dalam hak asasi manusia (HAM) dalam bekerja disuatu perusahaan. Dalam hal ini karyawan memiliki kewajiban sebelum melakukan pekejaan yaitu melakukan absensi kehadiran melalui finger print yang sudah disediakan oleh perusahaan. Sehingga dengan absensi karyawan dapat mengetahui gaji yang harus diterima oleh masing-masing karyawan.

Keterlambatan penggajian karyawan sering terjadi pada PT. Dwi Pratama Teknik karena, proses penginputan absensi masih dilakukan secara manual dengan Microsoft Excel yang memiliki kelemahan dalam hal dan waktu yang diperlukan cukup lama pada proses penginputan data serta kesalahan perhitungan oleh admin PT. Dwi Pratama Teknik, sehingga data harus dicatat atau diproses berulang kali dalam upaya menyusun laporan gaji karyawan.

Hal ini, gaji yang diterima karyawan sering terjadi keterlambatan dan kadang tidak sesuai dengan jumlah absen karyawan. Akibat dari banyak kompetitor dalam era globalisasi ini mengharuskan perusahaan untuk mengatasi masalah penggajian karyawannya agar mencegah berkurangnya produktivitas perusahaan dengan menggunakan sistem informasi penggajian yang terkomputerisasi.

Merujuk pada permasalahan diatas maka, diperlukan sebuah aplikasi penggajian karyawan untu PT. Dwi Pratama Teknik yang dapat mempermudah admin keuangan dalam melakukan proses perhitungan penggajian melalui data absensi yang didapat dari setiap hari kerja sehingga, admin keuangan tidak perlu lagi melakukan perhitungan lagi secara manual dari perhitungan periode-periode sebelumnya. Diharapkan dengan adanya aplikasi penggajian karyawan dapat mempercepat proses penggajian karyawan serta mempermudah admin keuangan dalammelakukan rekapan gaji dan rekapan laporan keuangan yang ada di PT. Dwi Pratama Teknik.

\section{TINJAUAN LITERATUR}

\section{2.1.Rangkuman Penelitian}

Penelitian terdahulu dilakukan oleh Endang Septiana, M Yazed Vebriandi yang berjudul "Sistem Informasi Pengolahan Data Penggajian Pegawai pada PT. Aditec Cakrawiyasa Palembang" [1]. Berdasarkan penelitian adanya aplikasi pengolahan data penggajian pegawai ini dapat membantu dan mempermudah pengolahan data sertamengurangi kesalahan dalam pendataan danpembuatan laporan data.

Penelitian terdahulu dilakukan oleh M Azmi yang berjudul "Rancang Bangun sistem Informasi Penggajian honorarium dan Pegawai Yayasan Nurul Huda Kecamatan Batanf Tuaka" [2]. Berdasarkan Penelitian untuk merancang sistem informasi penggajian honorarium guru dan pegawai yayasan nurul huda kec. Batang Tuaka dan menghasilkan laporan penggajian guru dan pegawai.

Penelitian terdahulu dilakukan oleh Ria Wulandari, Aditya Giyantono, Agus Gunawan yang berjudul "Rancangan Bangun Penggajian Berbasis Web pada PT. Surganya Motor Indonesi." [3]. Berdasarkan penelitian dengan adanya sistem aplikasi berbasis web dapat mengurangi pekerjaan keuangan admin dan bermanfaat sebagai monitoring agar tidakterjadinya keterlambatan dala pemberian gaji.

Penelitian terdahulu dilakukan oleh Lia Kumala Sari, Jaka Permadi yang berjudul "Aplikasi Penggajian Berbasis Web PT. Tirta Sukses Perkasa." [4]. Berdasarkan penelitian aplikas sudah diuji fungsionalitasnya menggunakan black-box testing dengan tingkat keberhasilan sebesar $82.35 \%$.

Penelitian terdahulu oleh Lasimin, Abd Haq, Verry yang berjudul "Sistem Informasi Penggajian PT. Kalisha Utama Ghani Cilacap menggunakan Framework Laravel" [5]. Berdasarkan Penelitian ini pengujian yang dilakukan dengan metode black-box menunjukan semua modul dapat berfungsi dan 
DOI: $10.52362 /$ jmijayakarta.v1i4.545

terhubung dengan database tanpa adanya kegagalan koneksi database.

Penelitian terdahulu oleh Sudika Diski Sitohang, Edi Sumarya, Hary Irwan yang berjudul "Analisis Sistem Informasi Penggajian Sebelum dan Sesudah Penerapan Sistem Attendance Manajement" [6]. Berdasarkan Penelitian hasil dari analisis sistem yang sudah diterapkan lebih unggul dari sistem sebelumnya.

(c) (i)

This work is licensed under a Creative Commons Attribution 4.0 International License. http://journal.stmikjayakarta.ac.id/index.php/JMIJayakarta 
DOI: $10.52362 /$ jmijayakarta.v1i4.545

Penelitian terdahulu oleh Sena Matina, Tora Fahrudin, Renny Sukawati yang berjudul "Aplikasi Manajemen Pasien dan Penggajian Karyawan berbasis Web" [7]. Berdasarkan Penelitian hasil dari sistem yang sudah diterapkan, dapat mempermudah dan mengefisiensi serta membantu dalam proses penggajiannya.

Penelitian terdahulu oleh Peni Supriatin, Nina Meliana yang bejudul "Sistem Informasi Penggajian Karyawan pada Perusahaan Outsourcing PT. Essei Perbama" [8]. Berdasarkan Penelitannya sistem penggajian berbasis web akan memudahkan danmeminimalisir kesalahan yang mungkin terjadi.

Penelitian terdahulu oleh Ali Muhammad Baihaqi, Sri Mardiyati, Ulfah Pauziah yang berjudul "Perancangan Sistem AplikasiPenggajian Karyawan pada Yayasan Akmal" [9]. Berdasarkan Penelitiannya setelah melakukan pengujiannya secara implementasi aplikasi ini dapat membantu memenuhi kebutuhan suatu proses penyimpanan data- data karyawan serta dapat membuat sistem lebih baik dalam hal penggajian.

Penelitian terdahulu oleh Iedam Fardian Anshori Ali Mulyawan yang berjudul "Perancangan Sistem Informasi Penggajian Berbasis Web pada PT. Wibee Indoedu Nusantara" [10]. Berdasarkan Penelitiannya dengan dibangunnya aplikasi penggajian karyawan berbasis web dapat membuataktivitas lebih efektif dan efisien dalam pekerjaan.

Penelitian terdahulu Musa Jaya, Lusi Ariyani yang berjudul "Sistem Informasi Penggajian Guru pada SMK Respati 1 Jakarta" [11]. Berdasarkan hasil dari penelitiannya sistem ini dapat membantu sekolah dalam menerapkan sistem yang lebih baik dan mempermudah pekerjaan serta meningkatkan kelancaran proses perhitungan gaji guru secaratepat, cepat dan akurat.

Penelitian terdahulu Ade Setiawan, Helti Nur Aisyiah yang berjudul "Analisis Sistem Informasi Akuntansi Penggajian diindustri mebel ABC" [12]. Berdasarkan hasil penelitian walaupun sistem penggajian pengupahan belum sepenuhnya terkomputerisasi namun demikian sudah berjalan efektif darisegi kerja, informasi, ekonomi, keamanan, effisien, dan pelayanan.

Penelitian terdahulu Andronias Siregar yang berjudul "Perancangan Sistem Informasi Penggajian berbasis Web pada CV. Alona Jaya" [13]. Berdasarkan hasil penelitian prosespengolahan data secara terkomputerisasi cenderung lebih mudah dan hasil pengolahan data mempunyai tingkat keakuratan yang lebihbaik.

Penelitian terdahulu Dwipa Handayani, Dian Hartanti yang berjudul "Sitem Informasi E-Payroll Karyawan Universitas Bhayangkara Jakarta Raya menggunakan metode waterfall berbasis android" [14]. Berdasarkan hasilpenelitian dengan adanya sistem ini penympaian informasi kepada karyawan lebih efisien, efektif serta membantu kepercayaan antara manajemen dan keuangan untuk melihat data yang dilaporkan secara periodik.

Penelitian terdahulu Deasty Kartika Sari, Greenda Souandi Rabia, Inge Handriani yang berjudul "Sistem Pengelolaan Kehadiran dan Penggajian menggunakan Pyment Gateway pada Perusahaan Jasa Kosultan IT" [15]. Berdasarkan hasil penelitian agar meningkatkan keakuratan dalam perhitungangaji karena sistem mempunyai perhitungan yang intensif.

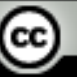

This work is licensed under a Creative Commons Attribution 4.0 International License.

http://journal.stmikjayakarta.ac.id/index.php/JMIJayakarta 
DOI: $10.52362 /$ jmijayakarta.v1i4.545

Tujuan penelitian ini dari sistem informasi pemodelan PIECES yaitu untuk menganalisa dari sistem menggunakan manual ke sistem web. Manfaat penelitian dengan menggunakan metode PIECES ini juga kontribusi yang bermanfaat yaitu:

\subsection{Pengertian Metode PIECES}

a. Metode PIECES ini menggunakan enam variable evaluasi yaitu Performance, Information, Economic, Control, Efficiency, Service berikut Penjelasan singkat dari masing-masingvariabel.

b. Performance

Menilai apakah proses yang dilakukan masih bisa sitingkatkan kenerjanya lagi atau tidak untuk menyelesaikanserangkaian proses untukmenghasilkan output.

c. Information Menilai apakah prosedur yang ada saatini masih bisa diperbaiki sehingga informasi yang didapat semakin baik, akurat, lengkap dan dapat disajikan secara tepat waktu.

\section{d. Economic}

Melihat prosedur yang ada saat ini apakah masih bisa ditingkatkan penggunaanya atau tidak dengan sistem yang ada saat ini.

e. Control

Menilai sistem yang dipakai saat ini tidak bisa ditingkatkan karena tidak adanya pengamanan, sehingga data- data yang tersimpan dapat dirubah.

f. Efficiency

Menilai dengan prosedur yang saat ini masih bisa diperbaiki denganmengubah ke sistem yang lebih baik lagi agar tercapai dengan peningkatan effisiensi operasi.

g. Service

Menilai dengan prosedur yang saat ini masih bisa diperbaiki denganmengubah ke sistem yang lebih baik untuk mencapai peningkatanlayanannya. 
DOI: $10.52362 /$ jmijayakarta.v1i4.545

\section{METODE PENELITIAN}

\subsection{Use Case Diagram Penggajian}

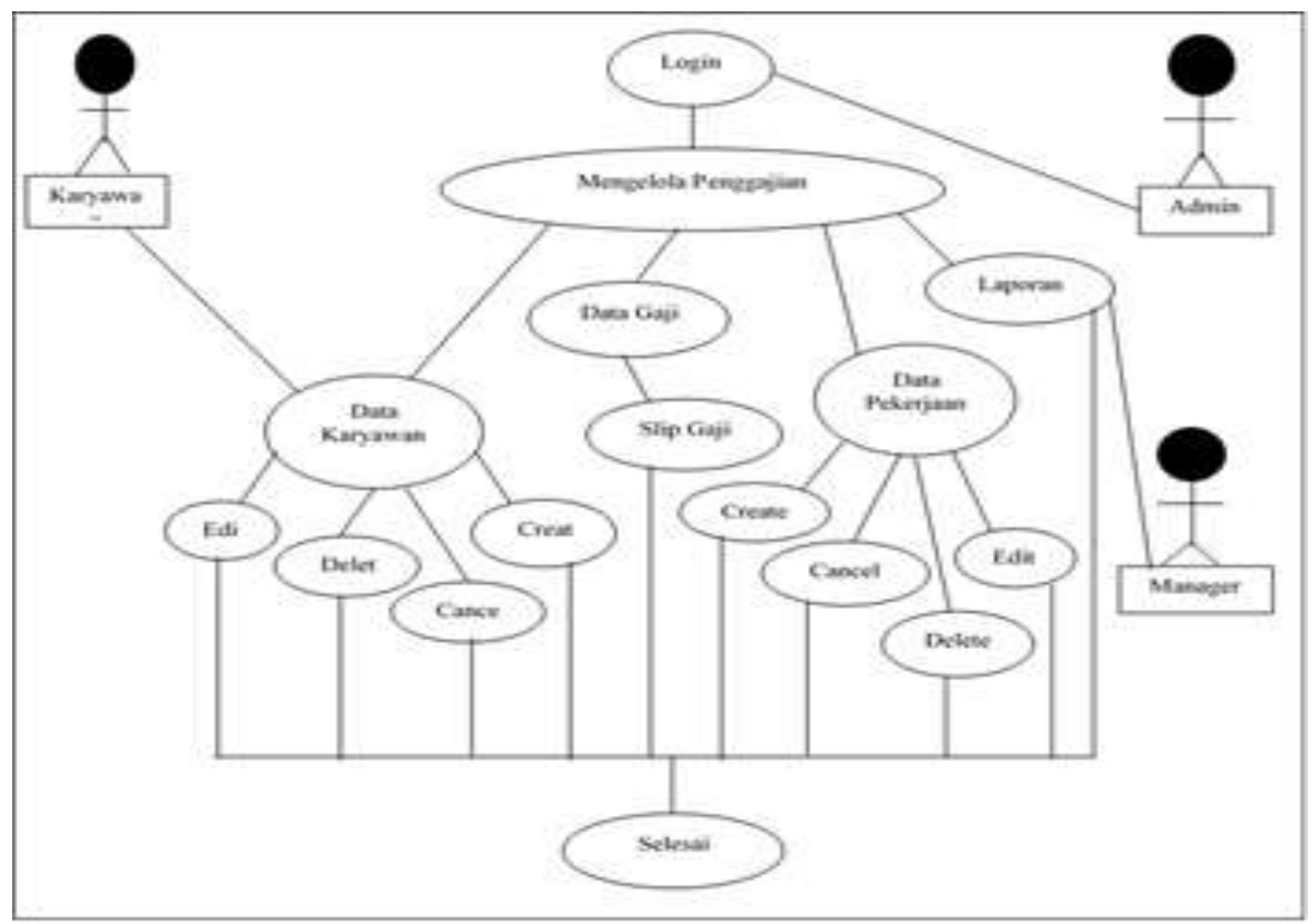

Gambar 1 Use Case Diagram

Dalam sistem ini terdapat 3 user yaitu sebagai berikut:

1. Admin melakukan pengelolaan dalam aplikasi PT. Dwi Pratama Teknik yang meliputi data karyawan, data pekerjaandan gaji karyawan.

2. Manager melakukan pengecekanlaporan terhadap gaji karyawan.

3. Karyawan menerima gaji dan dapatmelihat slip gaji serta datanya. 
DOI: $10.52362 /$ jmijayakarta.v1i4.545

\subsection{Flowchart Sistem yang di usulkan}

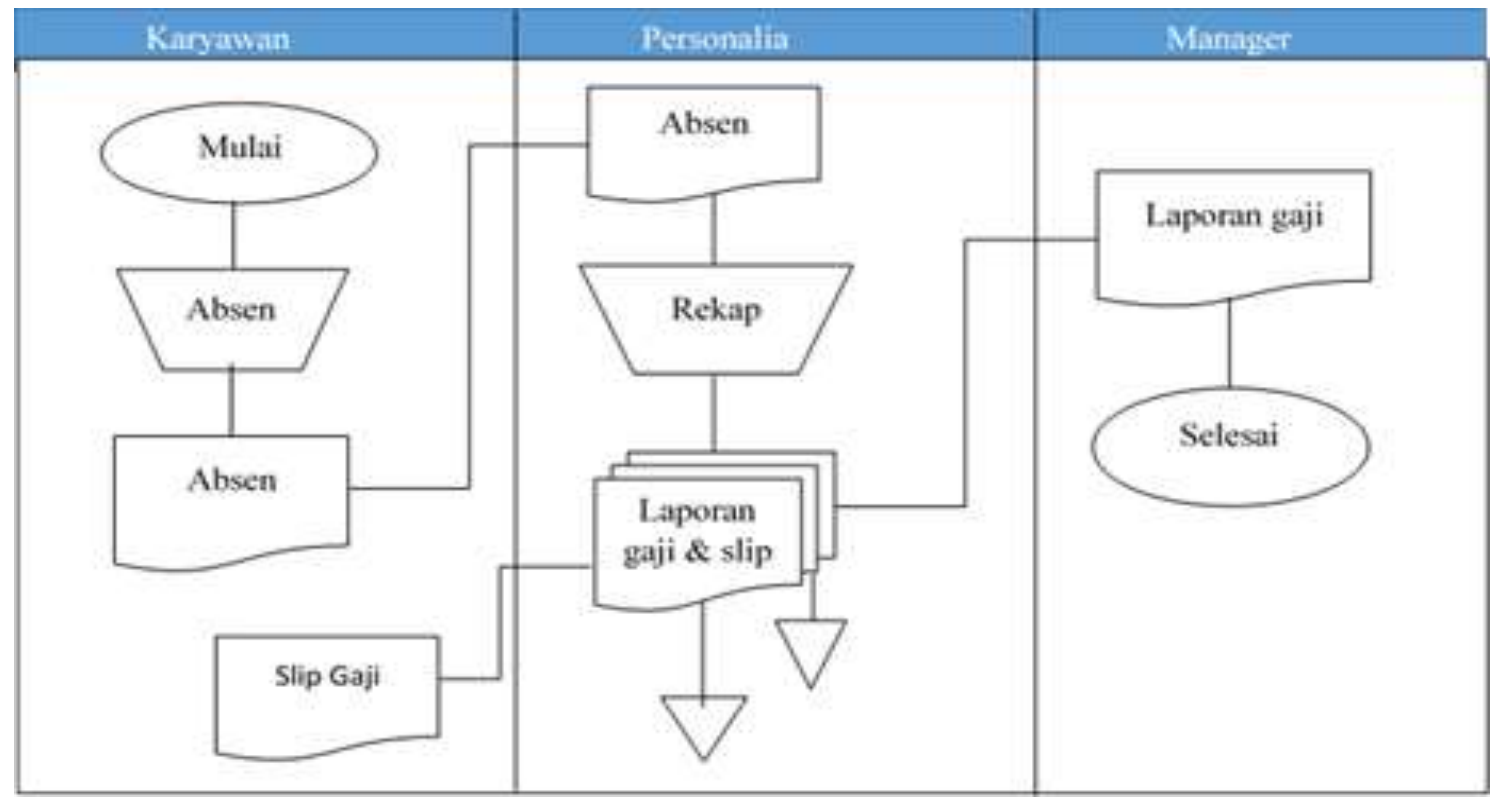

\section{Gambar 2 Flowchart SistemPenggajian}

\subsection{Metode Analisis PIECES}

Manfaat dari penelitian ini dengan metode PIECES agar memberikan kontribusi yang bernmanfaat. Menyatakan bahwa metode yang sedang digunakan adalah metode Performance, Information, Economic, Control, Efficiency, Service (PIECES) sebagai berikut:

a. Performance

Kemampuan sistem dalam menyelesaikan tugasnya untuk memasukan data-data dan melakukan perhitungan gaji karyawan dengan cepat dan tidak memakan banyak waktu.

b. Information

Lebih cepat dan mudah untuk mencari serta menyimpan data-data gaji karyawan karena sudah tersususn rapih sesuai dengan filenya.

c. Economic

Dengan menilai sistem atas biaya dan keuntungan yang akan didapatkan dari sistem yang diterapkan, sistem ini akan memberikan penghematan operasional bagi perusahaan.

d. Control

Dengan dibuatnya sistem ini data-data karyawan terjaga dengan aman, tidak ada yang bisa membuka, merubah, dan mengambilnya selain admin.

e. Efficiency

Berhubungan dengan sistem ini yang dapat digunakan secara optimal dan baik.

f. Service

Dengan adanya sistem ini dapat memberikan pelayanan yang baik dan dapat megkoodinasikan aktivitas dalam melakukan pengelolaannya. Contohnya penilaian yang baik: tidak terlambat dalam membrikan infomarsi terhadap karyawan. 
DOI: $10.52362 /$ jmijayakarta.v1i4.545

\subsection{Analisa Sistem}

Sitem penggajian merupakan salah satu hal yang penting dalam hak asasi manusia dalam suatu pekerjaan. Dengan didukung oleh teknologi berbasis web, Agar sistem penggajian ini dapat memudahkan bagian keuangan untuk melakukan rekapan dan laporan keuangan yang ada di PT. Dwi Pratama Teknik.

\section{a. Visi dan Misi}

a. Bekerja secara profesional dan propotional.

b. Berkompetisi global dalam kompetensi.

c. Berorientasi pada target profit.

d. Kesejahteraan bersama.

e. Peduli anak yati piatu dan dhuafa.

\section{HASIL DAN PEMABAHASAN}

\subsection{Tampilan login.}

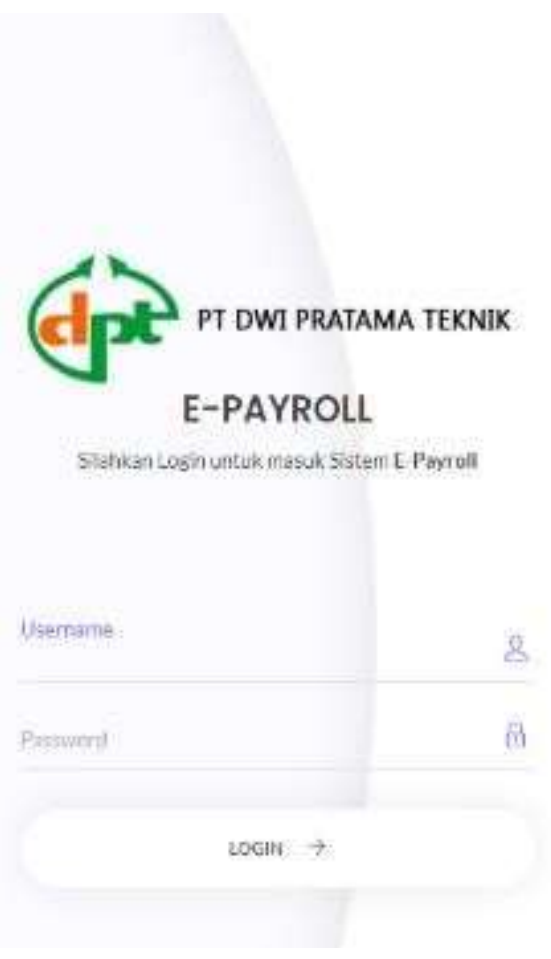

Gambar 3 Login 
DOI: $10.52362 /$ jmijayakarta.v1i4.545

\subsection{Tampilan Form Menu}

Halaman ini adalah halaman yang pertama kali muncul saat user ingin masuk ke aplikasi.

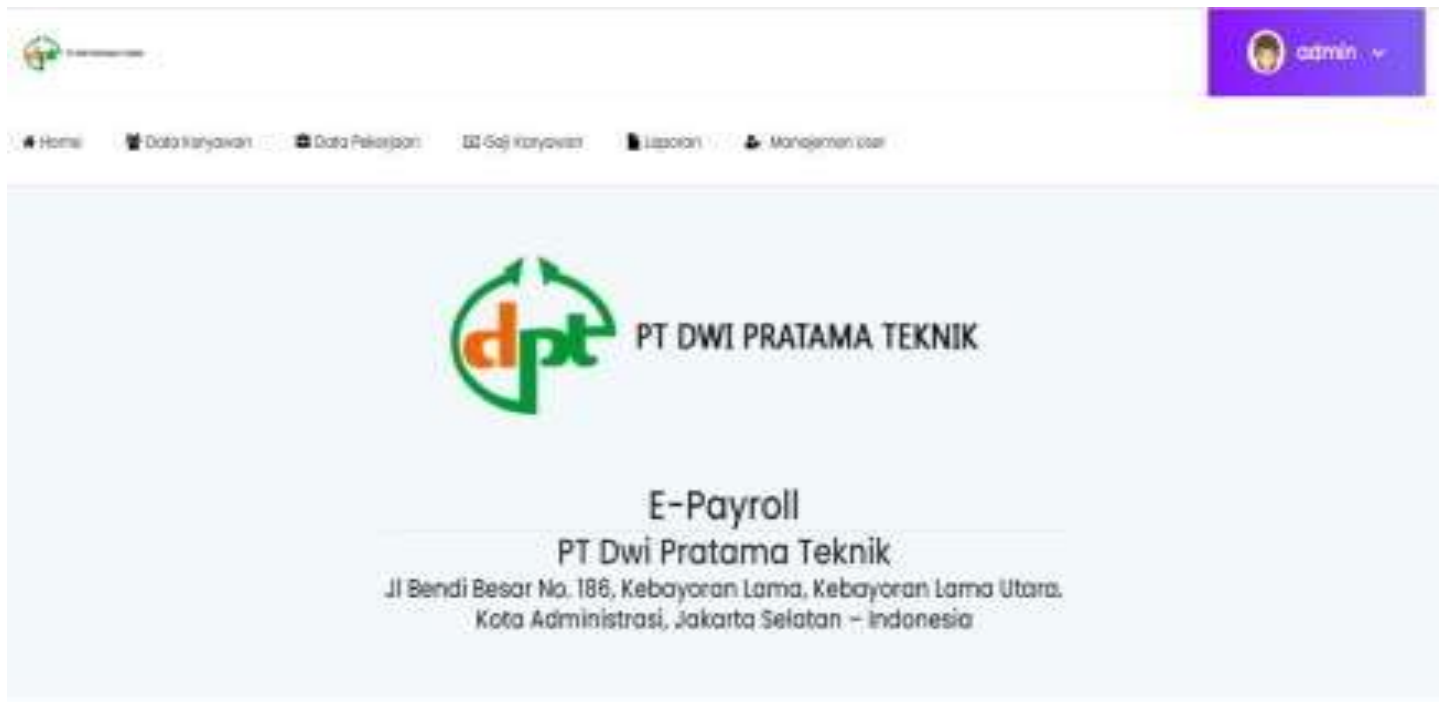

\section{Gambar 4 Form Menu}

\subsection{Tampilan Data Karyawan}

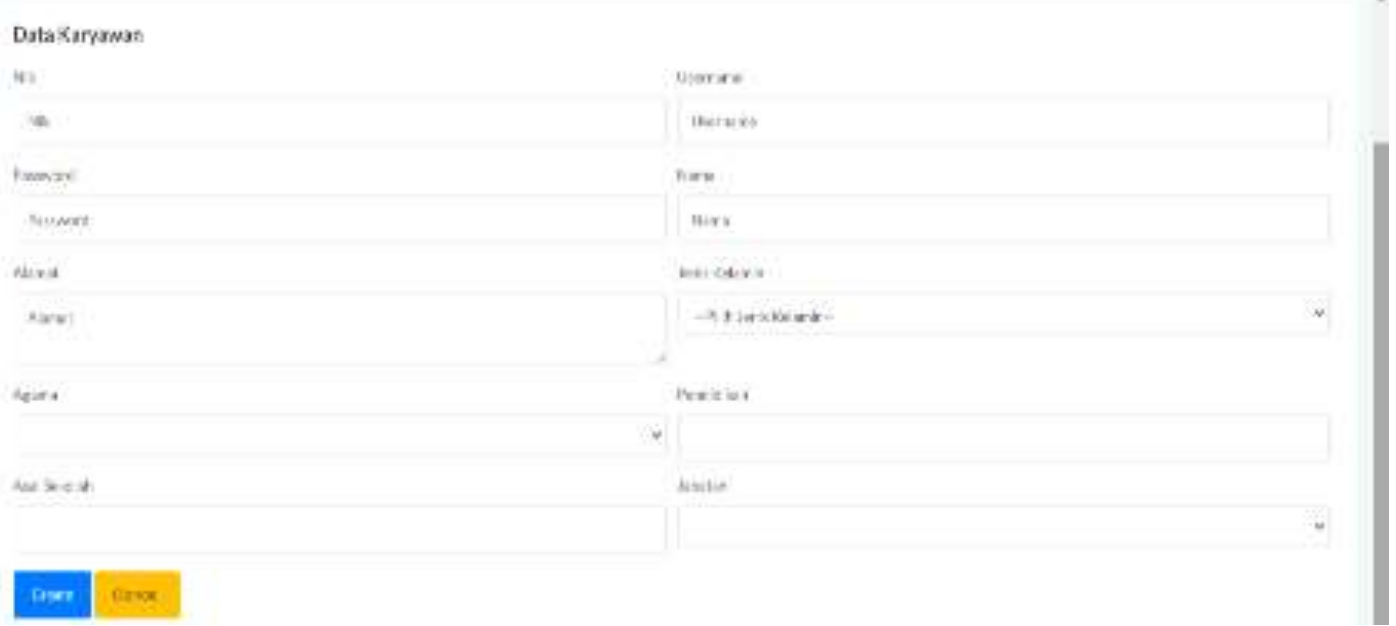


DOI: $10.52362 /$ jmijayakarta.v1i4.545

\section{Gambar 5 Data Karyawan}

\subsection{Tampilan Gaji Karyawan}

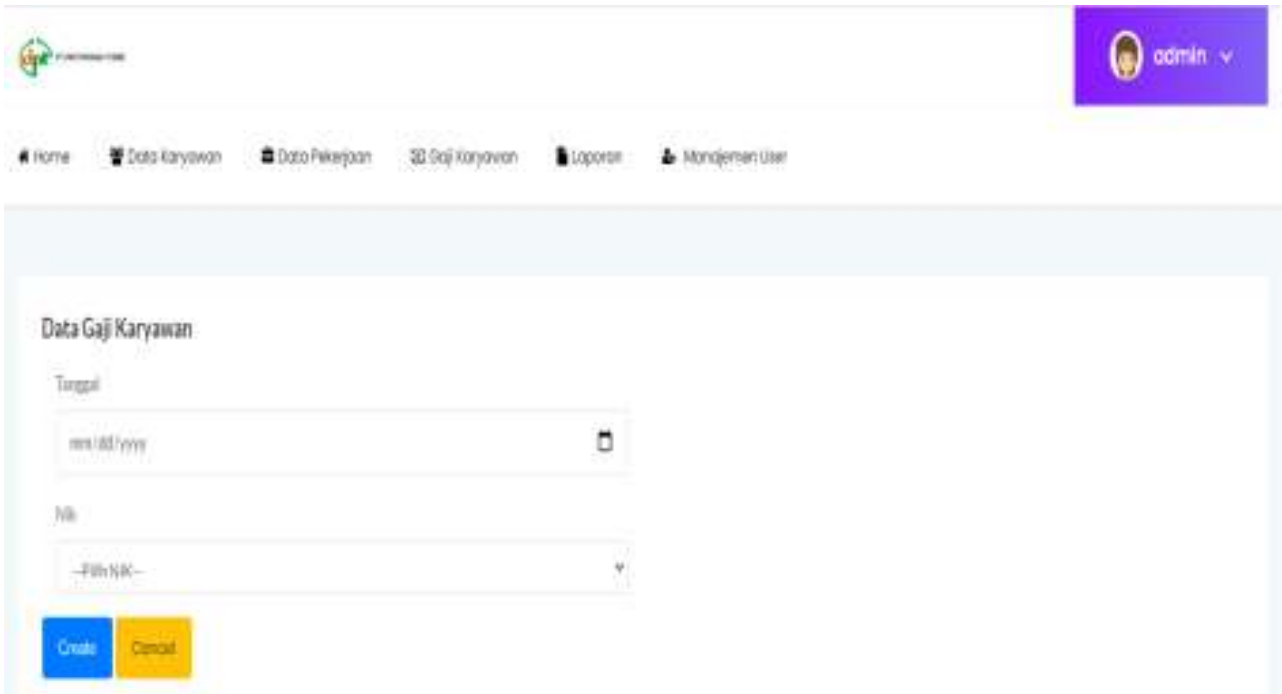

Gambar 6 Gaji Karyawan

\subsection{Tampilan Data Pekerjaan}

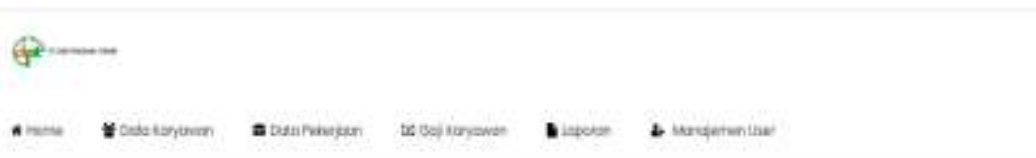

Data Pekeriaan

ieutin

asipacos

Havias

cosit.

Bamusiketems

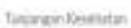

formanifunirim

lins

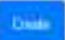

This work is licensed under a Creative Commons Attribution 4.0 International License.

http://journal.stmikjayakarta.ac.id/index.php/JMIJayakarta 
DOI: $10.52362 /$ jmijayakarta.v1i4.545

\section{Gambar 7 Data Pekerjaan}

\subsection{Tampilan Slip Gaji}

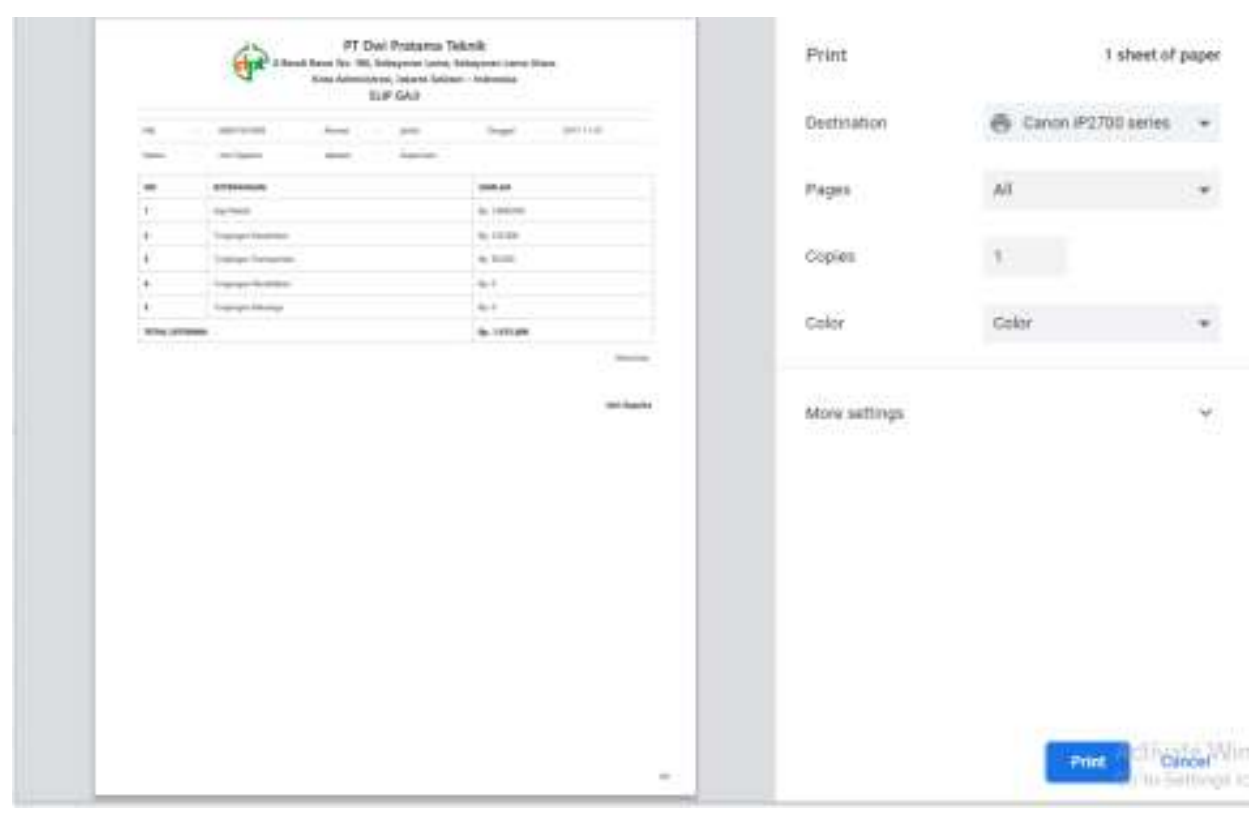

Gambar 8 Slip Gaji

\section{KESIMPULAN}

Berdasarkan hasil pengujian dan analisis dengan menggunakan aplikasi web pada PT. Dwi Pratama Teknik dapat disimpulkan bahwa:

1. Dengan menggunakan metode PIECES dapat menjawab permasalah sistem penggajian yang ada di perusahaan PT. Dwi Pratama Teknik.

2. Dengan adanya sistem ini memberikan pelayan yang baik bagi karyawannya karena dapat melihat data serta slip gaji.

3. Aplikasi ini hanya dapat menginput satu kali data saja.dan seluruh tombol yang ada diaplikasi telah sesuai dengan fungsinya. 
DOI: $10.52362 /$ jmijayakarta.v1i4.545

\section{REFERENSI}

[1] Ade Setiawan, Helti Nur Aisyiah. 2019. Analisis Sistem Informasi Akuntansi Penggajian di Industri Mebel ABC. Jurnal Akuntansi.

[2] Andronias Siregar. 2020. Perancangan Sistem Informasi Penggajian Berbasis Web pada CV. Alona Jaya. Jurnal Indonesia Sosial Teknologi.

[3] Ali Muhammad Bayhaqi, Sri Mardiyati, Ulfah Pauziah. 2021. Perancangan Sistem Aplikasi Penggajian Karyawan pada Yayasan Al-Akmal. Jurnal Riset dan Aplikasi Mahasiswa Informatika.

[4] Deasty Kartika Sari. 2020. Sistem Pengelolaan Kehadiran dan Penggajian Menggunakan Patment Gateway pada Perusahaan Jasa Konsultan IT. Jurnal Ilmu Komputer dan Informatika.

[5] Dwipa Handayani, Dian Hartanti. 2020. Sistem Informasi E-Payroll Karyawan Universitas Bhayangkara Jakarta Raya menggunakan metode Waterfall berbasis Android. Jurnal Information System For Educators and Profesionals.

[6] Endang Septiana, M Yazed Vebriandi. 2021. Sistem Informasi Pengolahan Data Penggajian Pegawai (Studi Kasus PT. Aditec Cakrawiyasa Palembang). Jurnal Information System and Computer Scince.

[7] Iedam Fardian Anshori, Ali Mulyawan. 2021. Perancangan Sistem Informasi Penggajian berbasis Web pada PT. Wibee Indoedu Nusantara.

[8] Lasimin, Abd Haq, Verry. 2020. Sistem Informasi Penggajian PT. Kalisha Utama Ghani Cilacap menggunakan Framework Laravel. Jurnal Information Management For Educators and Profesionals.

[9] Lia Kumala Sari, Jaka Permadi. 2018. Aplikasi Penggajian berbasis Web PT. Tirta Sukses Perkasa. Jurnal Sains dan Informatika.

[10] M Azmi. 2015. Rancang Bnagun Sistem Informasi Penggajian Honorarium Guru dan Pegawai Yayasan Nurul Huda Kecamatan Batang Tuaka. Jurnal Sistemasi.

[11] Musa Jaya, Lusi Ariyani. 2021. Sistem Informasi Penggajian Guru pada SMK Respati 1 Jakarta. Jurnal Riset dan Aplikasi Mahasiswa Informatika.

[12] Ria Wulandari, Aditya Giyantono, Agus Gunawan. 2017. Rancang Bangun Penggajian Karyawan berbasis Web pada PT. Surganya Motor Imdonesia. Jurnal Cerita.

[13] Sena Martian, Tora Fahrudin, Reny Sukawati. 2020. Aplikasi Manajemen Paisen dan Penggajian Karyawan berbasis Web. Jurnal e-proceeding of applied science.

[14] Sudika Diski Sitohang, Edi Sumarya, Hery Irwan. 2019. Analisis Sistem Informasi Penggajain

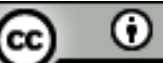

This work is licensed under a Creative Commons Attribution 4.0 International License.

http://journal.stmikjayakarta.ac.id/index.php/JMIJayakarta 
DOI: $10.52362 /$ jmijayakarta.v1i4.545

sebelum dan sesudah penerapan sistem Attandance Mnagement (studi kasus PT. Pollux Barelang Mega Superblock). Jurnal Profiensi.

[15] Peni Supriatin, Nina Meliana. 2021. Sistem Informasi Penggajian Karyawan pada Perusahaan Outsoucing PT. Essei Perbama. Jurnal Sibernetika. 